\section{Amateurism and Our Common Concern for Biodiversity}

\section{Timothy McLellan}

Treating the environment as a common resource often implies not only local, but also supralocal, even global, collectives of concerned stakeholders. While engaging with local actors, these stakeholders frequently insist on the need for a 'professional' approach. Examining an international project aimed at introducing biologically diverse agroforestry in a county in southwest China, this essay describes a more 'amateur' approach adopted by one international organisation. It argues that this amateurism demonstrates that, even within global professional organisations, there is an appetite for a new, more spontaneous, approach that values local knowledge and practices.

This article is based upon work supported by the National Science Foundation under Grant No. 1357194, The Cornell East Asia Program, and Cornell's Mario Einaudi Center for International Studies. To ensure the anonymity of my research subjects, I use pseudonyms for all institutional, personal and place names.
Treating the environment as a common resource often implies not only local, but also supra-local, even global collectives of concerned stakeholders. The Convention on Biological Diversity, for example, asserts that 'the conservation of biological diversity is a common concern of humankind'. An agroforestry project in Qingshan township, Yunnan province, was one such effort to establish the environment and biodiversity as a common concern for a global community of actors.

A Western cosmetics company, Metelli, sponsored the project. Launched about a decade ago, the project's goal was to introduce ecologically complex, biologically diverse agroforestry to Qingshan. According to a Metelli corporate social responsibility officer, since the company's products depend on nature for their ingredients, Metelli has a responsibility to give back to the environment. Here, Metelli sees itself as a responsible stakeholder alongside local communities, and attempts to insert itself as a collaborator in the management of Qingshan's environmental commons.

This article is based on two years' participant observation at the Institute for Farms and Forests (IFF), an international agricultural research organisation who participated

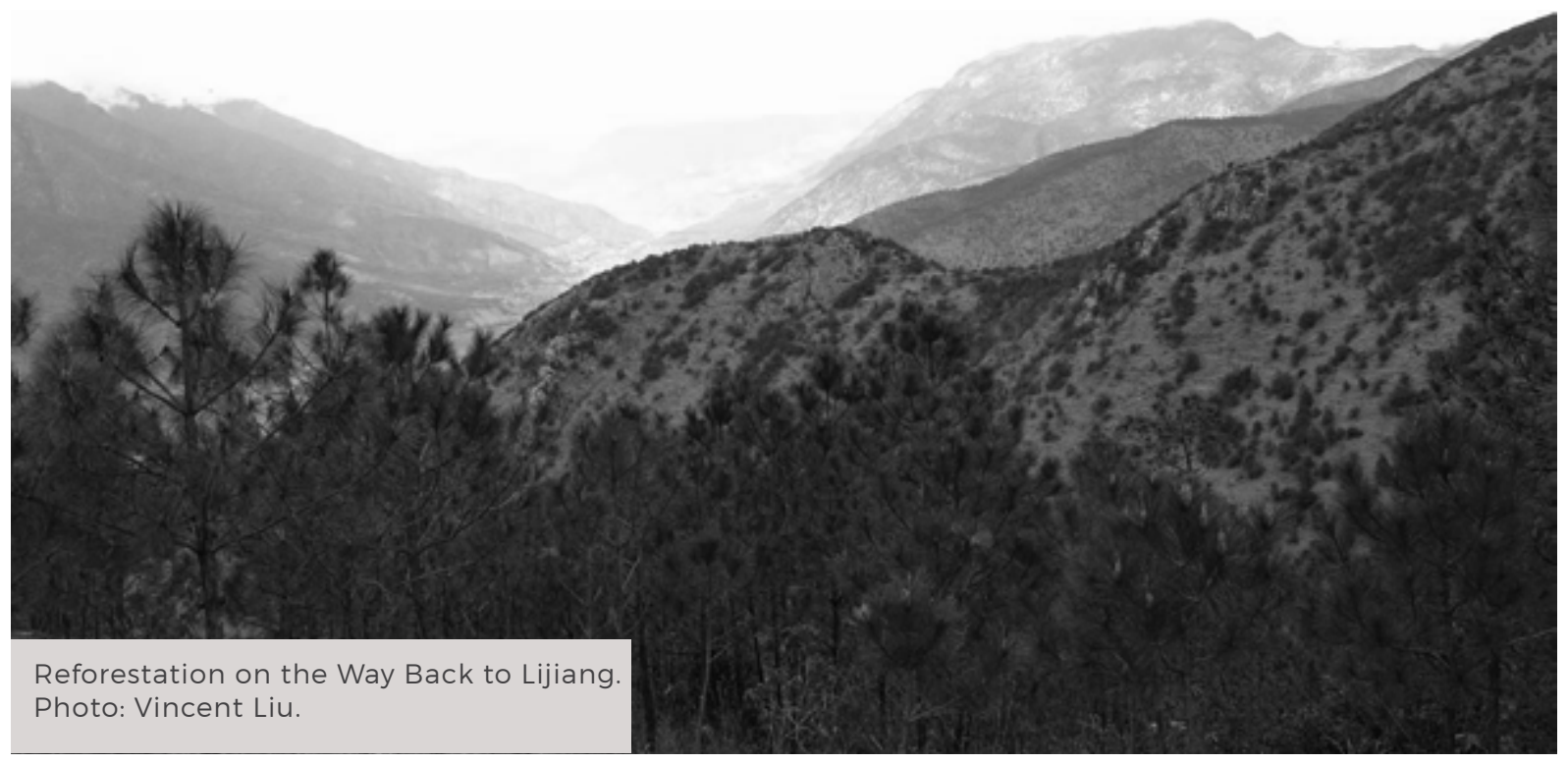


in the project. Inspired by critiques of academic professionalisation, and associated explorations of the virtues of amateurism, I describe the amateur engagement that IFF attempted to bring to this project. I argue that this amateurism demonstrates that, even within global professional organisations like IFF, there is an appetite for what Anna Tsing calls 'creat[ing] scenes that exceed or escape professionalization.’

\section{Pursuing Amateurism}

To implement Metelli's vision for Qingshan, several organisations were recruited. First, a Western NGO with experience in agroforestry, Arboreus, and a local NGO called Shehui. Several years into the project, Metelli and Arboreus had become concerned by Shehui's lack of agri-environmental expertise. IFF was therefore recruited to the project, bringing with it its experience in agroforestry and soil management. In contrast to the other project partners, IFF's involvement was rather informal. IFF had a lucrative contract with Metelli to facilitate laboratory research on local medicinal plants with the potential for use in cosmetics. As such, when they offered assistance to Metelli's Qingshan project, IFF asked only for funds to cover travel expenses. The resulting absence of the kind of formal deliverables that ordinarily tie IFF's funding promised IFF scientists an unusual degree of latitude.

Having provisionally devised soil management practices for Qingshan, and established participatory principles according to which these ideas should be communicated, the IFF team (of which I was a member) ran several workshops in Qingshan. While IFF's enthusiasm for 'participation' embraced a central tenant of contemporary development professionalism, IFF's designs for the project were out of sync with certain contemporary trends. First, Qingshan workshops were each designed from scratch and as unique events.
Workshops did not adhere to a previously established protocol, nor did IFF staff imagine their workshops to be replicable on a wider scale. This contrasted with certain other projects where IFF employed protocols or 'toolkits' that had been designed to be transferable across time and space.

Second, IFF scientists envisioned the process of learning from Qingshan farmers and getting to know the landscape over which they sought to establish a common concern as a slow and gradual process. Workshops were organised sporadically, and in response to the project as it unfolded. Each visit was approached as a further opportunity to learn. This contrasts with certain iterations of participatory rural appraisal (PRA) delivered as rapid, one-off workshops. In such versions of PRA, Terry Rambo suggests, development professionals 'claim to understand everything by sponsoring a three-to-four-day rapid appraisal exercise'. Here, participation is co-opted by the very forms of professional 'arrogance' Robert Chambers intended for it to address.

In the Qingshan case, far from the 'understanding [of] everything' promised by certain PRA toolkits, IFF scientists' ad hoc workshops created a degree of anxiety. Whereas transferable toolkits often imply a certainty in what should be done, the IFF team were at each stage anxious as to whether their ad hoc activities would perform as hoped: Had we really generated a space for dialogue, or were farmers simply telling us what we wanted to hear? Would the proposed soil management strategies really benefit Qingshan? In this respect, whereas scientists are often accused of adopting 'technologies of hubris', the anxieties generated by IFF's ad hoc approach suggest the seeds of what Sheila Jasanoff calls 'technologies of humility'.

If contemporary research and development professionalism is characterised by replicability, scalability, transferability, rapidness, and self-confidence; I am going to describe the ad hoc, single-site, one-off, slow, 
anxiety-inducing, and often deeply personal engagement that IFF pursued as a form of amateurism.

\section{The Project Falls Apart}

A soil management plan developed at an early workshop was for winter cover crops to be planted in-between the rows of notyet-harvested primary crops. Susanna, an IFF soil scientist, had proposed this early planting strategy as a solution to the farmers' experience that cover crops did not survive Qingshan's dry winters. When it came to the appropriate time to sow cover crops, however, we discovered via Shehui's local project manager, Xuejian, that the farmers had decided to delay planting until after harvest. According to Xuejian, since the rains in Qingshan had begun very late that year, farmers expected that rains would also finish later than usual. As such, the farmers reasoned, they could afford to postpone cover crop planting until after harvest.

When this message was relayed to Susanna she was dismayed. She feared that the rains might not continue late, and having persuaded Qingshan farmers to give cover crops another try, she did not want them to fail. Susanna and her colleagues, moreover, were frustrated that Shehui had taken several weeks to inform IFF of the farmers' new approach. In this respect, IFF's attempt to situate itself within a larger collective was challenged by the fact of its exclusion from a significant decisionmaking process. In a sense, this exclusion denied IFF's implicit claim on Qingshan's biodiversity as an object of common concern.

IFF's response was to organise a further workshop in Qingshan. The difficulties in making this workshop happen, however, came from beyond Qingshan. IFF had initially arranged a workshop directly with a community leader in Qingshan, but Xuejian contacted IFF to cancel the workshop. Shortly thereafter, we received a communication from Arboreus explaining that all IFF activities in Qingshan must be pre-approved by both Shehui and Arboreus. The workshop did eventually go ahead, but following the workshop, wrangling continued amongst Shehui, Arboreus, and IFF. Whereas IFF scientists had anticipated and embraced the practical and ethical challenges of establishing relations with Qingshan farmers, the unexpected labour of maintaining relationships with extra-local partners emerged as an impossible headache.

Some IFF colleagues attributed the project's failure to the incompetence of their project partners. In one instance, Xuejian explained to IFF scientists that Arboreus's training in Qingshan had attempted to impress upon farmers the importance of three metre spacing between trees-a guideline, Xuejian told us, that took no account of tree species or location. For IFF scientists, this absurdly global approach to tree propagation confirmed Arboreus's ignorance. The failure of the collaboration, however, can also be attributed to an incongruity between the approaches of IFF and its project partners. As well as their incompetence, Arboreus's tree-spacing guidance showed their professionalism: it reflected their understanding of environmental sustainability as a global, scalable process.

Embracing development professionalism, Arboreus were constantly contemplating how their activities might be replicated across ever-larger scales. Indeed, this was part of the reason they wanted not only prior notification of IFF's activities, but also written reports after each visit to Qingshan. On one occasion, impressed by a soil management booklet Susanna had produced specifically for Qingshan farmers, Arboreus asked whether IFF might create a similar set of booklets for them to use globally.

IFF, by contrast, approached the project much more narrowly: as a project in Qingshan. We were seldom distracted by the question of how to replicate or upscale activities in Qingshan. This is not to say that IFF is not 
ordinarily subjected to such imperatives. At a recent regional planning meeting, for example, an IFF communications officer described how the organisation must learn from marketing professionals and build a global brand for itself. Many IFF staff members were uncomfortable with such demands. Indeed, part of the Qingshan project's appeal to IFF staff was perhaps that it presented an opportunity to work outside of this global scale and the accompanying imperatives of professional research for development. In this sense, the Qingshan project promised the chance to play the amateur.

By drawing attention to IFF's amateurism I do not mean to imply that, unimpeded by their supra-local partners, IFF would inevitably have made the project a resounding success, or that amateurism escapes the contradictions and tensions inherent in efforts to make biodiversity a common concern in a world that is fundamentally unequal. Nevertheless, like China Scherz's account of a Catholic charity's refusal to adopt the logic of development donors, IFF's all too brief flirtation with what I have called amateurism shows that, even within a prominent international organisation like IFF, there are seeds of activities that 'exceed or escape professionalization'.

\section{A Victory for Professionalism}

In this Qingshan case, however, Arboreus's professionalism won through. Shortly after the shambles of IFF's negotiations to run a workshop, Arboreus commissioned an audit of the project. One outcome of the audit was for Metelli to belatedly act upon an IFF suggestion to establish experimental agroforestry plots in Qingshan. IFF responded with a detailed proposal for the plots, but some at IFF half hoped Metelli would decline to fund the proposal, and thereby give IFF an excuse to leave the project. The headache of collaboration with supra-local partners had led to a loss of faith in the project ever running smoothly. Moreover, the professional imperatives to formalise project plans and project goals, as well as to undergo audits and manage budgets, robbed the project of the amateur quality that had initially sparked IFF staff's now fading commitment to, and hope in, the project.

Transferring on a flight back to the United Kingdom after completing fieldwork, I spotted photos of farmers planting trees in Qingshan displayed at a Metelli airport concession. As an example of Metelli's corporate social responsibility, the display invited consumers to share in Metelli's concern for global biodiversity. In effect, the invitation to purchase Metelli cosmetics was also an invitation to join the collective the company had established with Qingshan farmers, and to thereby participate in the sustainable management of environmental commons. Of course, from the point of view of IFF scientists, this collective and its management of Qingshan's biodiversity had been no great success. Metelli's marketing strategy, however, may serve as a reminder that just as challenging as it can be to establish meaningful collaborations around environmental commons, constructing the façade of a global collective can be rather easy. Indeed, in an era where organisations like IFF are turning to marketing in their efforts to professionalise, we should perhaps wonder if environmental commons would be better off in the hands of amateurs.

\section{Timothy McLellan}

Timothy McLellan is a PhD candidate in anthropology at Cornell University. He has a BA in Law and Chinese from The School of Oriental and African Studies, and an MSc in Law and Anthropology from The London School of Economics. 